\title{
Production of ceramic tiles by combining Moroccan phosphate mine tailings with abundant local clays
}

\author{
Fatima Zahra Boutaleb ${ }^{1}$, Nadia Boutaleb ${ }^{1, *}$, Bouchaib Bahlaouan ${ }^{1,2}$, Deblij Sanaa ${ }^{1}$ and Said El Antri $^{1}$ \\ ${ }^{1}$ Hassan II University of Casablanca. Laboratory of Biochemistry, Environment, and Agri-Food, URAC36, \\ 20650, Morocco \\ ${ }^{2}$ Higher Institutes of the Nursing Professions and Techniques of Health (ISPITS), Casablanca 22500, Morocco
}

\begin{abstract}
This study offers an easy, economical, and ecological solution to manufacture a ceramic faience product with excellent mechanical properties by combining Moroccan phosphate mine tailings and two abundant local clays. The use of these clays alone was inconceivable because they do not generate a material that meets the mechanical requirements.

A mixture design strategy conducted the optimization of the formulation. Therefore, ten tests were carried out. The ceramic tiles produced are characterized by their physical properties (water absorption, shrinkage), mechanical properties (flexural strength), and surface properties (observation by scanning electron microscopy).

The results show that phosphate mine tailings improve the mechanical properties of ceramic tiles. Industrial use at a rate of $33 \%$ in formulas based on abundant local clays could, therefore, be envisaged to design faience products, conforming to the mechanical and technical requirements. This mode of production contributes to saving nonrenewable natural resources, preserving the environment and aligns with the principle of sustainable development.
\end{abstract}

Keywords: Moroccan phosphate; mine tailings; recovery; ceramic industry; mechanical properties; mixture designs.

\section{Introduction}

The exploitation of phosphate mines in Morocco constitutes an important vector of economic and social development. The aim is to meet the demand for natural resources to develop and improve other industrial activities (chemical, agricultural sector, etc.), as well as contribute to improving the quality of life of the population and to the development of the country.

Morocco holds a good part of the world reserves with more than three-quarters of reserves. The phosphate deposits are mainly found in four zones ${ }^{1-5}$ :

- The Khouribga zone (Plateau of OuledAbdoun)

- The Maskala basin (Marrakech)

- The Bengruerir and Youssoufia region (the Gantour basin)

- The Layoune-BouCraa zone

The Ouled Abdoun basin of Khouribga is one of the sedimentary veins most abundant in phosphates. It contains $44 \%$ of the country's reserves or around 26.8 billion tonnes of phosphate ${ }^{6,7}$. Mining causes environmental changes. The mines exploit the deposits, but at the end of the process, leave significant quantities of solid and liquid discharges and huge mountains of mine tailings that are dumped in the mine area so as not to interfere with the extraction activity. The exploitation activities strongly influence the landscape of the site environment, in addition to this, other impacts on the biological (vegetation, fauna) and climatic (atmosphere) components of the receiving environment. Responsible management is essential to mitigate or minimize environmental impacts, a mine must manage the waste generated on the operating site.

From a regulatory context point of view, Morocco consecrates for the exploitation of mines, the Dahir of 9 Rajab 1370 (April 6, 1951) modified for the adoption of new law No. 33.13 (May 23, 2016).

Article 2 of the law classifies phosphates among category 8 and considers it as mines and natural deposits of mineral substances. In its articles 52, 56, 59,61 and 62, the law refers to the standardization of operation according to an HSE (Health, Safety, Environment) system, and obliges the completion of the impact study on the environment to obtain 
operating licenses, and to have an abandonment plan to preserve the environment and ensure sustainable development and rehabilitation of the site after exploitation ${ }^{8,9}$.

Given that there are no publications on the recycling of Moroccan phosphate mine tailings, and intending to move towards cleaner mines, this work consists of studying an alternative way of recovering this waste in the manufacture of ceramic tiles. Some works in the literature are interested in the recovery of waste and by-products from phosphate mining operations:

Loutou et al. (2013) ${ }^{10}$ studied the recovery of phosphate sludge generated by Moroccan phosphate rock enrichment factories in the manufacture of light aggregates (LWA). The LWA are granular and porous products with a lower density. They are used, amongst others, in acoustic and thermal barriers, lightweight concrete, geotechnical works, gardening, and hydroponics. The sludge should contain quartz, carbonates, and clays. Such assemblage of minerals could be suitable for the manufacturing of lightweight aggregates (LWA).

Sfar Felfoul et al. (2004) ${ }^{11}$ and Boughzala et al. (2015) ${ }^{12}$ worked on phosphogypsum recovery. It is a by-product of the fertilizer industry obtained during the attack of natural calcium phosphates with sulfuric acid in production phosphate fertilizer.

Moukannaa et al. (2018) ${ }^{13}$ studied the use of phosphate mining residues for the production of geopolymers with new physical and mechanical properties for the field like cement and concrete, fire resistance materials, thermal insulator, marine structures, high tech composites, and radioactive and toxic waste containment.

His study was carried out using the mixing plan simplex strategy, the objective being to optimize the formulation and improve the mechanical properties of ceramic tiles based on our preliminary study, which demonstrated the favorable effect phosphate mine tailings on mechanical properties ${ }^{4,5}$.

This work offers an easy, economical and ecological solution to manufacture a ceramic faience product with excellent mechanical properties by combining Moroccan phosphate mine tailings with abundant local clays. The use of these clays alone was inconceivable because they do not generate a material that meets the mechanical requirements.

The use of phosphate mine tailings as an alternative raw material in the ceramic industry makes it possible to reduce the cost of the local product by compensating for part of the construction materials used, and so to conserve non-renewable natural resources. Finally, this study raises awareness of the need and importance of industrial formulation to identify the optimal mixture to be developed for manufacturing ceramic products that meet the requirements.

\section{Experimental}

\subsection{Preparation of mixtures}

The phosphate mine tailings (S), is a by-product resulting from the exploitation of phosphate by the Office Chérifien du Phosphate (OCP) in the Béni-Idir area (the Khouribga area in Morocco). For the preparation of the compositions intended for the manufacture of ceramics, local natural clays (C1 and C2) are used. These are two varieties of abundant quarry clays from the El Gara region of Morocco.

The tests were organized according to the strategy of mixture designs, without the constraint of centroid simplex with 10 experimental points. Table 1 presents the different formulas studied.

Table 1. The mixture formulas studied, based on local and abundant natural clays $(\mathrm{C} 1, \mathrm{C} 2)$ and the phosphate mine tailings $(\mathrm{S})$.

\begin{tabular}{|c|c|c|c|}
\hline Mixture & $\mathbf{C 1}$ & $\mathbf{C 2}$ & $\mathbf{S}$ \\
\hline $\mathbf{1}$ & $100 \%$ & $0 \%$ & $0 \%$ \\
\hline $\mathbf{2}$ & $0 \%$ & $100 \%$ & $0 \%$ \\
\hline $\mathbf{3}$ & $0 \%$ & $0 \%$ & $100 \%$ \\
\hline $\mathbf{4}$ & $50 \%$ & $50 \%$ & $0 \%$ \\
\hline $\mathbf{5}$ & $50 \%$ & $0 \%$ & $50 \%$ \\
\hline $\mathbf{6}$ & $0 \%$ & $50 \%$ & $50 \%$ \\
\hline $\mathbf{7}$ & $33 \%$ & $33 \%$ & $33 \%$ \\
\hline $\mathbf{8}$ & $67 \%$ & $17 \%$ & $17 \%$ \\
\hline $\mathbf{9}$ & $17 \%$ & $67 \%$ & $17 \%$ \\
\hline $\mathbf{1 0}$ & $17 \%$ & $17 \%$ & $67 \%$ \\
\hline
\end{tabular}

\subsection{Method of manufacturing tiles}

In a porcelain ball grinding jar (500 grams of capacity), the mixture is kneaded for 25 minutes, with approximately $4 \%$ water and $1 \%$ deflocculant (Fluicer®). The slip thus produced is placed in an industrial dryer for 30 minutes at $110^{\circ} \mathrm{C}$ until 
completely dry. The product obtained is ground, sieved, then rewetted by spraying. The wet powder thus obtained is introduced into a manual tableting press. Under a constraint of 200 bars, several pellets are generated (ten for each formula). These are dried at $170^{\circ} \mathrm{C}$ for 25 minutes in an industrial roller drier. This achieves a residual water content of less than $1 \%$, a favorable condition to avoid cracks during firing. A final stage of firing is carried out; it lasts approximately 40 minutes, during this stage, the temperature gradually reaches $1200^{\circ} \mathrm{C}$.

\subsection{Chemical and particle size analysis}

The chemical analysis for the determination of the oxides was made by X-ray fluorescence, using a BRUKER S8® TIGER spectrometer with a dispersive wavelength detector (WDXRF) for $\mathrm{C} 1, \mathrm{C} 2$ and The phosphate mine tailings $\mathrm{S}^{14}$.

The particle size analysis is carried out by dry sieving for the sandy fraction, then by sedimentation for the silty and clay fractions according to the method described by the United States Department of Agriculture ${ }^{15,16}$.

\subsection{Physicochemical and mechanical characterization of materials}

The determination of the mechanical properties for the materials manufactured was carried out following ISO 10545-4 (2019) standard ${ }^{17}$ using a Shimadzu ${ }^{\circledR}$ single-column machine, EZ LX series ( 7 tests for each formula).
The firing shrinkage is determined by calculating the difference in dimensions, using an electronic caliper, before and after firing in an industrial rotary oven by the ISO 10545-3 (2018) standard ${ }^{18}$.

The percentage of water absorption is calculated by weight difference before and after immersion in boiling water for 4 hours, under the ISO 10454-3 (2018) standard ${ }^{18}$.

\subsection{Microscopic observation of materials}

The surface analysis was carried out by SEM scanning electron microscopy observations. This analysis makes it possible to assess the granular compactness and cohesion. A Hirox SH-4000M device makes microscopic observations after the metallization of the surfaces.

\subsection{Statistical data analysis}

The mixture plan methodology, which makes it possible to establish a ternary with the isoresponse surfaces ${ }^{19}$ as well as a principal component analysis, are conducted. The graphics are made by STATISTICA® software.

\section{Results and Discussion}

Table 2 presents the results concerning the chemical characterization by $\mathrm{X}$-ray fluorescence spectrophotometry of clays $\mathrm{C} 1, \mathrm{C} 2$, and the phosphate mine tailings $\mathrm{S}$.

Table 2. Chemical compositions by X-ray fluorescence (in mass\%) of clays C1, C2 and S.

\begin{tabular}{|c|c|c|c|c|c|c|c|c|c|c|c|c|c|}
\hline & $\mathbf{S i O}_{2}$ & $\mathbf{A l}_{2} \mathbf{O}_{3}$ & $\mathbf{F e}_{2} \mathbf{O}_{3}$ & $\mathbf{C a O}$ & $\mathbf{M g O}$ & $\mathbf{K}_{2} \mathbf{O}$ & $\mathbf{N a}_{2} \mathbf{O}$ & $\mathbf{P}_{2} \mathbf{O}_{5}$ & $\mathbf{S O}_{3}$ & $\mathbf{T i O}_{2}$ & $\mathbf{M n O}$ & $\mathbf{B a O}$ & $\mathbf{F L}$ \\
\hline $\mathbf{C 1}$ & 55.70 & 17.00 & 6.25 & 3.95 & 2.70 & 4.55 & 0.40 & 0.10 & 0.13 & 0.80 & 0.15 & 0.06 & 7.04 \\
\hline $\mathbf{C 2}$ & 72.30 & 13.30 & 4.20 & 0.50 & 0.70 & 4.00 & 1.20 & 0.10 & 0.10 & 0.50 & 0.03 & 0.30 & 5.49 \\
\hline $\mathbf{S}$ & 7.41 & 0.71 & 0.32 & 46.45 & 1.25 & 0.14 & 0.57 & 24.13 & 1.06 & 0.10 & 0.02 & 0.02 & 17.06 \\
\hline
\end{tabular}

*fire loss at $1140^{\circ} \mathrm{C}$.

Chemical analysis (Table 2) of the mine waste rock shows high $\mathrm{CaO}(46.45 \%)$ and $\mathrm{P}_{2} \mathrm{O}_{5} \quad(24.13 \%)$ contents, against a low percentage of silica $\mathrm{SiO}_{2}$ (7.41\%) and alumina $\mathrm{Al}_{2} \mathrm{O}_{3}(0.71 \%)$. The high $\mathrm{CaO}$ content reflects the carbonated nature of the waste rock, confirmed by a considerable fire loss (17.06\%). According to the literature, the presence of carbonates stabilizes the acid-base environment and can lead to the formation of the refractory monolith, essential for thermal resistance ${ }^{14}$. On the other hand, the presence of alumina in clay materials generally helps to have a low shrinkage on drying, or even on baking and allows the manufacture of refractory materials after the passage at high temperature. It is, therefore, essential to use the phosphate mine tailings mixture with clays rich in alumina to have a balanced clay mixture. A relatively high value in $\mathrm{SO}_{3}$ is noted for the waste rock, the presence of this element reflects the richness of the medium in plastic materials ${ }^{20}$, which plays a vital role in improving the plasticity ${ }^{13,21}$.

\subsection{Particle size analysis}

The particle size analysis makes it possible to define various classes of materials regardless of their chemical composition. Table 3 presents the particle size distributions of the components $\mathrm{S}, \mathrm{C} 1$, and $\mathrm{C} 2$ used.

Table 3. Granulometry of clays $\mathrm{C} 1$ and $\mathrm{C} 2$ and the waste rock (S). Values expressed as a percentage.

\begin{tabular}{|c|c|c|c|}
\hline & Sand 50-2000 $\boldsymbol{\mu m}$ & Silt 2-50 $\boldsymbol{\mu m}$ & Clay $<\mathbf{2} \boldsymbol{\text { m }}$ \\
\hline S & $8 \%$ & $17 \%$ & $75 \%$ \\
\hline C1 & $15 \%$ & $25 \%$ & $60 \%$ \\
\hline
\end{tabular}


The particle size analysis (Table 3 and Figure 1) classifies $\mathrm{C} 1, \mathrm{C} 2$, and $\mathrm{S}$ among the category of fine clays according to the conventional classification of the United States Department of Agriculture ${ }^{15,16}$. This type of soil is characterized by high plasticity in the wet state or compactness in the dry state.

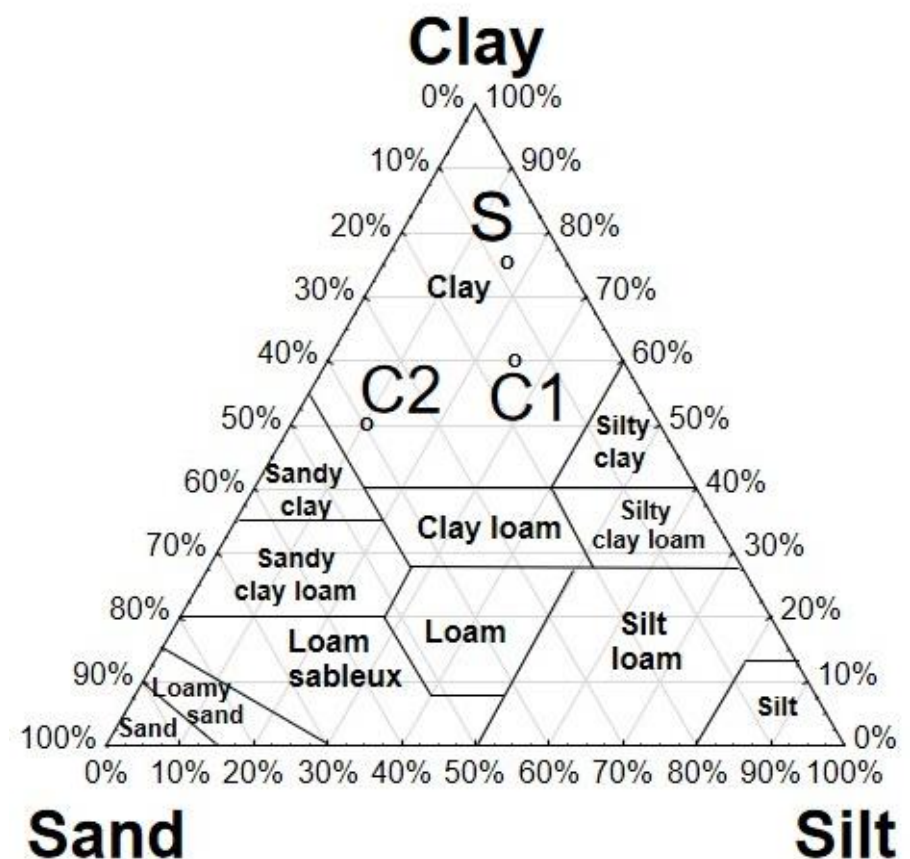

Figure 1. Classification, according to particle size, of $\mathrm{C} 1, \mathrm{C} 2$ and $\mathrm{S}$ in the classification triangle adopted by the United States Department of Agriculture (USDA) ${ }^{15}$

\subsection{Mechanical resistance and technical} properties of the tiles produced

Clays are materials, which have the particularity of undergoing variations in volume when they are found in dry or humid environments. Depending on their structure, these modifications are more or less important.

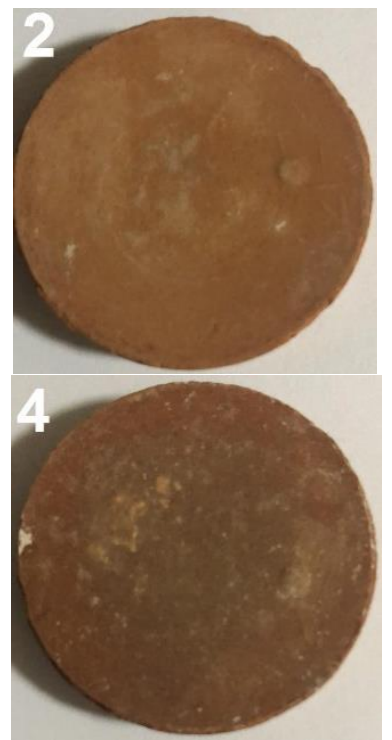



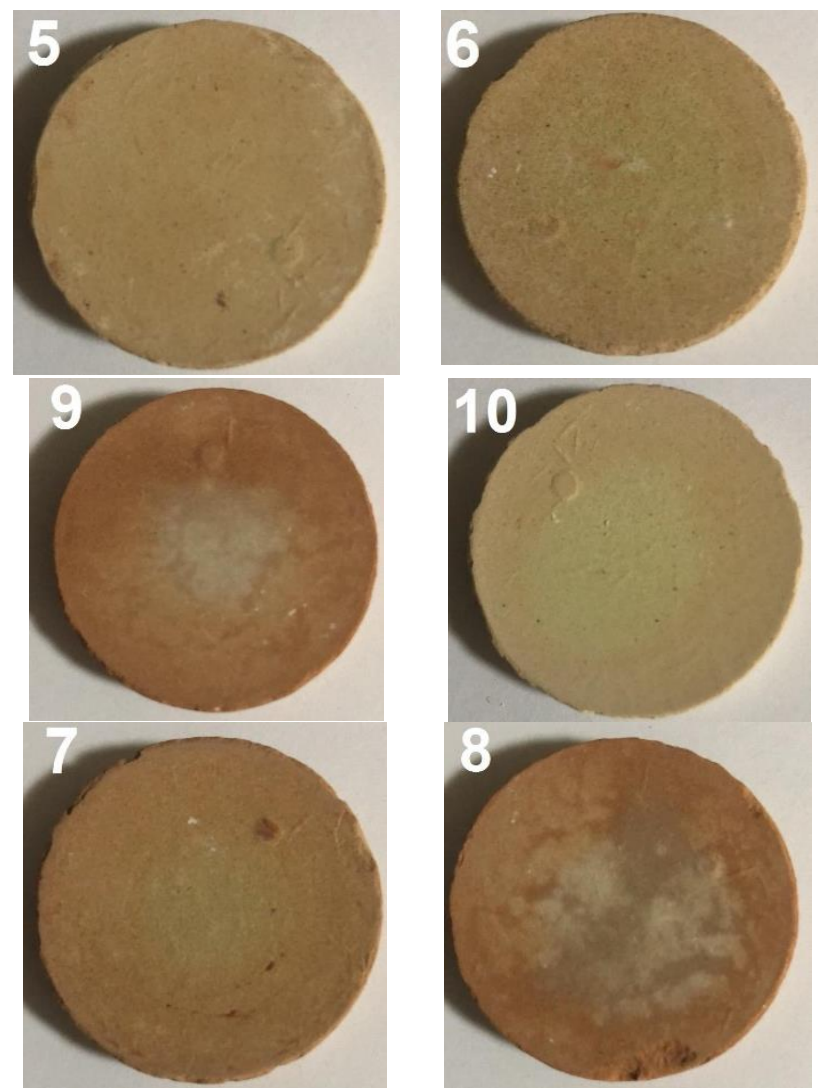

Figure 2. Dry pressing Specimen of ceramic tiles

On an industrial scale, this property has a considerable impact on the progress of the enameling process and the technical adaptation of the material to changes in the surrounding climate. Figure 2 shows the appearance of the tiles studied after the final firing step.

Table 4 presents the firing shrinkage and water absorption percentages for the materials tested.

Table 4. Mechanical resistance and technical properties of the tiles produced.

\begin{tabular}{|c|c|c|c|c|}
\hline Materials & Firing shrinkage $\mathbf{( \% )}$ & $\begin{array}{c}\text { Water } \\
\text { absorption }(\mathbf{\%})\end{array}$ & $\begin{array}{c}\text { Breaking force } * * \\
\mathbf{( N )}\end{array}$ & $\begin{array}{c}\text { Flexural strength } \\
\left(\mathbf{N} / \mathbf{m m}^{\mathbf{2}}\right)\end{array}$ \\
\hline $\mathbf{1}$ & $6.20 \pm 0.63$ & $14.53 \pm 0.60$ & 496.58 & 10.91 \\
\hline $\mathbf{2}$ & $3.70 \pm 0.70$ & $19.35 \pm 0.84$ & 504.21 & 13.95 \\
\hline $\mathbf{3}$ & $13.39 \pm 0.54 *$ & $19.21 \pm 0.80$ & 123.23 & 2.50 \\
\hline $\mathbf{4}$ & $7.38 \pm 1.56$ & $12.10 \pm 0.64$ & 46.74 & 1.22 \\
\hline $\mathbf{5}$ & $11.52 \pm 0.65 *$ & $16.27 \pm 0.75$ & 320.30 & 7.28 \\
\hline $\mathbf{6}$ & $8.87 \pm 0.61$ & $17.06 \pm 0.79$ & 362.48 & 8.47 \\
\hline $\mathbf{7}$ & $8.92 \pm 0.80$ & $16.56 \pm 0.80$ & 724.27 & 15.61 \\
\hline $\mathbf{8}$ & $8.39 \pm 0.60$ & $20.95 \pm 0.94$ & 452.42 & 9.75 \\
\hline $\mathbf{9}$ & $6.06 \pm 0.84$ & $18.35 \pm 0.75$ & 444.65 & 11.30 \\
\hline $\mathbf{1 0}$ & $11.36 \pm 2.98 *$ & $15.61 \pm 0.80$ & 53.19 & 1.06 \\
\hline
\end{tabular}

\section{* Significant difference}

** The breaking force is calculated by dividing the breaking load on a constant, which is a function of the shape of the material tested.

Ceramic tiles are classified in trade according to several groups. The mention of these is based on two criteria: the manufacturing method and the percentage of water absorption.
Two methods of manufacturing the tiles are distinguished: Method A - tiles produced by extrusion and Method B - tiles produced by dry pressing. We retain, for our case, the letter " $\mathrm{B}$ " to be capitalized in 
the group of tiles, to designate that these are tiles manufactured by dry pressing. In the same way, according to the percentage of absorption, ceramic tiles are classified according to 3 groups:

Group I - Tiles with a low absorption percentage $(\leq 3 \%)$. It includes for tiles produced by dry pressing:

The BIa group (absorption percentage $\leq 0.5 \%$ ) and the BIb group (absorption percentage $>0.5 \%$ and $\leq 3 \%$ ).

Group II - Tiles with average water absorption percentage ( $>3 \%$ and $\leq 10 \%)$. It includes for the tiles produced by dry pressing: The BIIa group (absorption percentage $>3 \%$ and $\leq 6 \%$ ) and the BIIb group (absorption percentage $>6 \%$ and $\leq 10 \%$ ).

Group III - This group includes tiles with a high percentage of absorption (>10\%).

On the other hand, during firing, a ceramic piece undergoes a firing shrinkage expressed by a percentage $(\%)$, a loss in diameter caused by the fusion of components that tend to fill the voids existing between the particles.

According to Table 4, all the materials have a water absorption percentage, which exceeds $10 \%$; they then form part of Group III ${ }^{22,17}$. For this range, which is not necessarily the first choice, the flexural strength of at least $15 \mathrm{~N} / \mathrm{mm}^{2}$ is imposed. We also note that the increasing integration of $(\mathrm{S})$ contributes to increasing

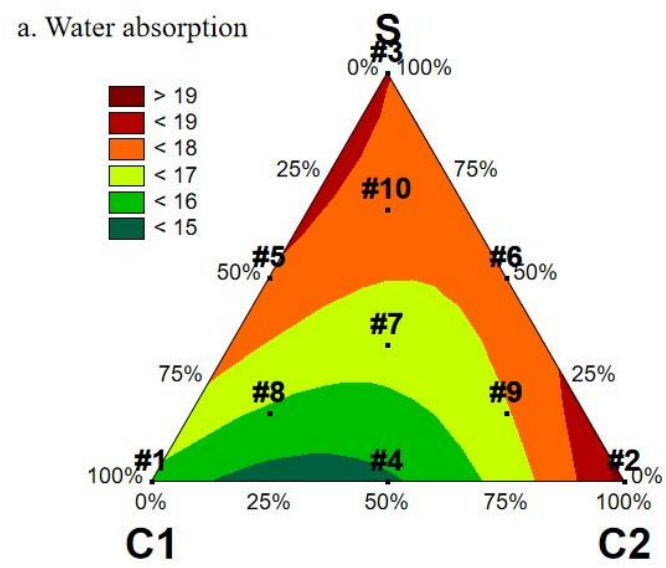

the percentage of water absorption. This is probably due to its richness in $\mathrm{CaO}$, and its low content in $\mathrm{SiO}_{2}$ and $\mathrm{Al}_{2} \mathrm{O}_{3}$ according to the results of the chemical analysis. The results of Table 4 show that only the respective tiles of formulas 3,5 , and 10 , which have a significant firing shrinkage.

In addition, the mechanical requirements are described according to the percentage of water absorption. The percentage of water absorption is, therefore, an essential prerequisite in the assessment of the mechanical conformity of tiles. In general, the higher the percentage of water absorption, the more it will be necessary to ensure a higher mechanical resistance ${ }^{22,17}$. According to the literature, for group III tiles, resistance (for a thickness $<7.5 \mathrm{~mm}$ ) is required flexural strength higher than $15 \mathrm{~N} / \mathrm{mm}^{2}$.

It is noted that only the material number 7, which satisfies the criteria and can be marketed according to the range of group III. We also note that the use of the 3 components $\mathrm{C} 1, \mathrm{C} 2$, and the phosphate mine tailings individually does not generate mechanically conventional materials.

The isoresponse surfaces presented in Figure 4 allow us to appreciate the correlation that may exist between the mechanical strength and the percentage of absorption of the tiles studied

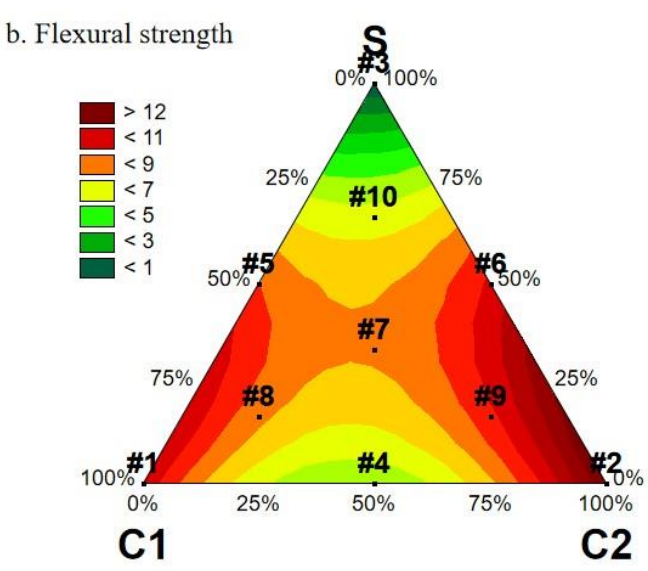

Figure 3. The isoresponse surfaces. (a) Water absorption (b) Flexural strength.

According to Figure 3, it can be seen that there is no obvious correlation between the percentage of water absorption and the resistance to bending. The best results are around formulation 7 . Indeed, this formula presents an unusual mechanical resistance with a relatively reduced absorption percentage. These findings are even more visible in the Biplot and the correlation circle in Figure 4.

Figure 3 also shows that the proportion of rock waste must not exceed $67 \%$, to having faience products with excellent mechanical properties. 

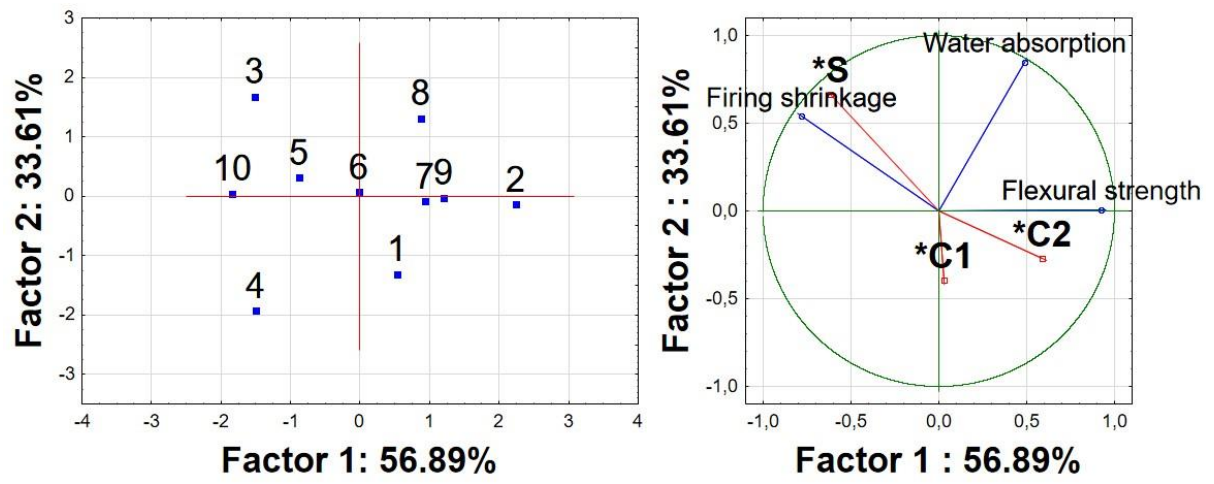

Figure 4. The Biplot consisting projection on PC 1 (56.89\%) and PC 2 (33.61\%) of cases, and the corresponding correlation circle

The Biplot and the correlation circle presented in Figure 4:

- Confirm the independence between the absorption percentage, the Firing shrinkage, and the mechanical resistance, a fact already underlined by the isoresponse surfaces (Figure 4).

- Show that the highest values for shrinkage are attached to individuals 3,5 , and 10 , and it is the addition of the phosphate mine tailings, which explains this observation (Figure 4).

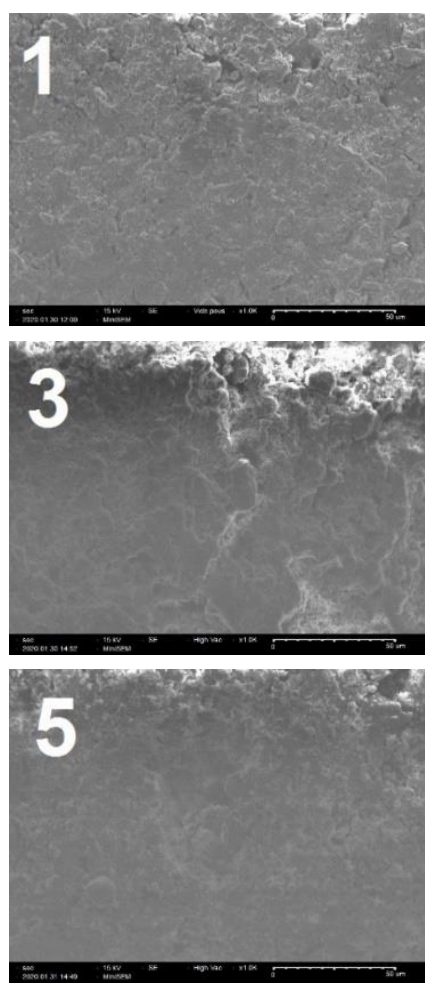

- Show that Materials 7, 8, and 9 with material 2 are the most relevant from mechanical resistance; on the other hand, material 7 has the lowest absorption percentage, and it is the richest phosphate mine tailings formula among these materials.

\subsection{Surface analysis of manufactured tiles}

The observation of the state of cohesion and the texture of the materials produced, carried out by scanning electron microscopy (SEM) is presented at the level of Figure 5. This observation allows the detection of microcracks within the clay matrix and decohesions at the interfaces with aggregates.
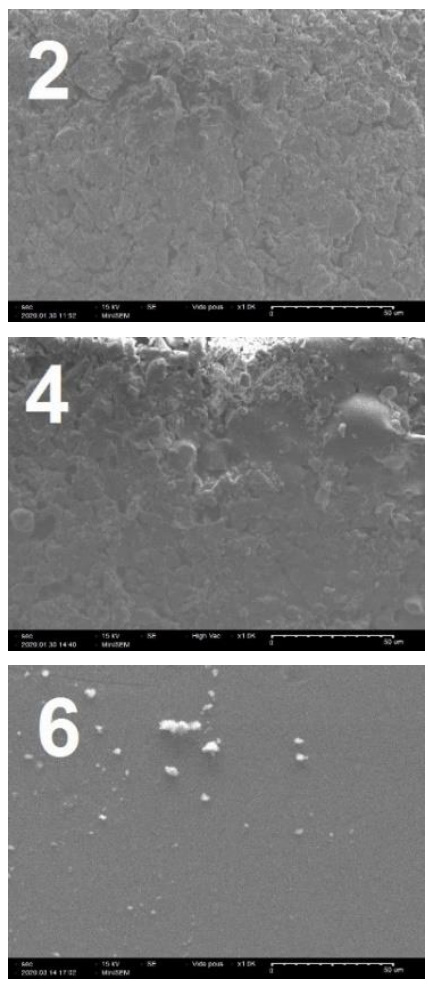

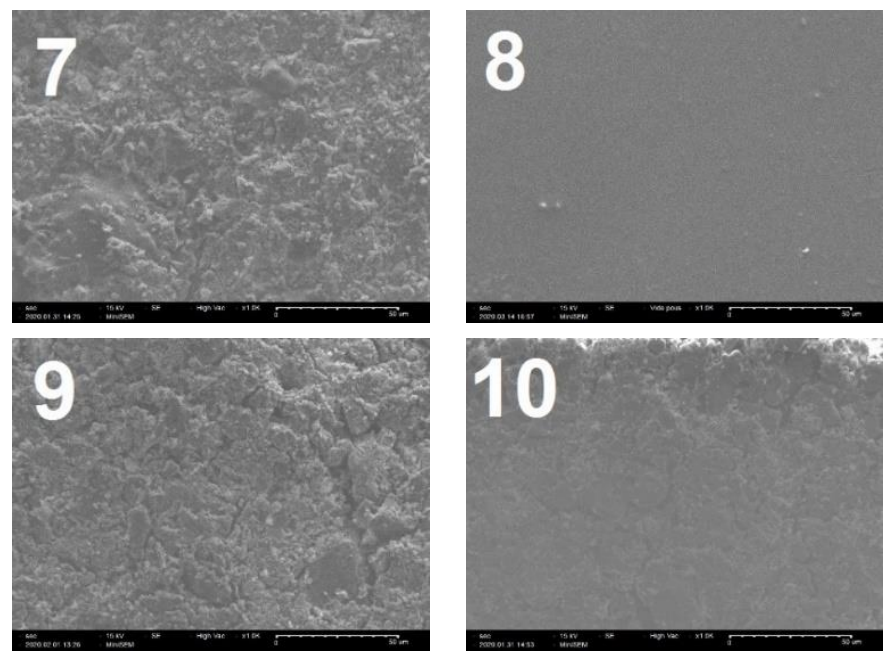

Figure 5. Observation in scanning electron microscopy at $1000 \mathrm{X}$ of the different ceramic materials.

3, 410 are the materials that have shown poor mechanical properties. These results agree with the SEM photo. These materials appear in the picture in Figure 5, not very cohesive and inhomogeneous. On the materials $1,2,7$, 9, we notice a somewhat comparable aspect in which the granules appear according to a more cohesive plastic aspect between the granules. The reliefs in the photos are probably due to the high density that particular materials can manifest during firing. The firing operation followed by cooling can be the source of a loss of volatile matter; this loss results in the formation of cavities and is generally the cause of significant densification ${ }^{23,24}$.

\section{Conclusion}

This study consists of an optimization essay by the strategy of mixture design simplex-centroid of the formula of ceramic faience products, made from Moroccan phosphate mine tailings combined with two abundant local clays.

The results show that to obtain a product that meets mechanical requirements, it is necessary to involve both the three components in the formulation. Indeed, all the formulas made up of $100 \%$, by only one of the components studied, or by their binary mixtures, presented relatively unfavorable results. The physicochemical and mechanical characterization shows that the integration of the phosphate mining waste must be around $33 \%$, as soon as their proportions begin to exceed $67 \%$, the mechanical properties of the faience products start to fall and become unfavorable.

The recycling of phosphate discharges in the ceramic field can be one of the means of management and recovery, combining ecological and economic aspects.

\section{Acknowledgments}

To the company Espano Cerame; at the Office Cherifien du Phosphate (OCP) - Beni-Idir phosphate production and enrichment unit (Khouribga); Research Center of Materials and Energy of the Hassan II University of Casablanca.

\section{References}

1- R. Hakkou, M. Benzaazoua, B. Bussière, Acid mine drainage at the abandoned Kettaramine (Morocco): 2. Mine waste geochemical behaviour, Mine Water and the Environment, 2008, 27, 160-170.

2- R. Hakkou, M. Benzaazoua, B. Bussière, Laboratory Evaluation of the Use of Alkaline Phosphate Wastes for the Control of Acidic Mine Drainage, Mine Water and the Environment, 2009, 28, 206-218.

3- R. Hakkou, M. Benzaazoua, B. Bussière, Valorization of phosphate waste rocks and sludge from the Moroccan phosphate mines: Challenges and perspectives, Procedia Engineering, 2016, 138, 110-118.

4- F. Boutaleb, N. Boutaleb, B. Bahlaouan, S. Deblij, S. El Antri, Effect of Phosphate Mine Tailings from Morocco on the Mechanical Properties of Ceramic Tiles, International Journal of Engineering Researc\&Technology, 2020, 9, 140-145.

5- F. Boutaleb, N. Boutaleb, B. Bahlaouan, S. El Antri, Valorisation du stérile d'exploitation des phosphates au Maroc dans la fabrication de carreaux céramiques, Techniques Sciences Méthodes, 2020, 2, 37-43.

6- N. Bardet, N. E. Jalil, F. de Lapparent de Broin, D. Germain, O. Lambert, M. Amaghzaz, A Giant Chelonioid Turtle from the Late Cretaceous of Morocco with a Suction Feeding Apparatus Unique among Tetrapods, PLoS One, 2013, 8, $1-10$

7- J. Yans, M. Amaghzaz, B. Bouya, H. Cappetta, P. Iacumin, L. Kocsis, M. Mouflih, O. Selloum, S. Sen, Y. Storme, E. Gheerbrant, First carbon isotope chemostratigraphy of the OuledAbdoun phosphate Basin, Morocco; implications for 
dating and evolution of earliest African placental mammals, Gondwana Research, 2014, 25, 257-269.

8- Dahir du 9 Rajab 1370 (6 avril 1951) relatif aux mines.

9- Loi ${ }^{\circ} 33.13$ sur les mines, Bulletin Officiel $n^{\circ}$ 6380 du 23 juillet 2015.

10-M. Loutou, M. Hajjaji, M. Mansori, C. Favotto, R. Hakkou, Phosphate sludge: Thermal transformation and use as lightweight aggregate material, Journal of Environmental Management, 2013, 130, 354-360.

11-H. Sfar Felfoul, M. Benouezdou, P. Clastres, Etude du phosphogypse de Sfax en vue d'une valorisation en technique routière, Colloque « Matériaux, Sols et Structures, MS ${ }^{2}, 2004$, 127-131.

12-K. Boughzala, A. Jaouadi, N. Fattah, K. Bouzouita, H. Ben Hassine, Traitement et valorisation des rejets de phosphates de Gafsa Treatment and Valorization of Waste Gafsa pohosphate, Revue science des matériaux, Laboratoire LARHYSS, 2015, 4, 13-31.

13-S. Moukannaa, M. Loutou, M. Benzaazoua, L. Vitola, J. Alami, R. Hakkou, Recycling of phosphate mine tailings for the production of geopolymers, J. Clean. Prod, 2018, 185, 891-903.

14-A. Manni, A. Elhaddar, A. El Bouari, I. E. El Hassani, C. Sadik, Complete characterization of Berrechid clays (Morocco) and manufacturing of new ceramic using minimal amounts of feldspars: Economic implication, Case Studies in Construction Materials, 2017, 7, 144-153.

15-ASTM, American Society for Testing Material, Standard Method for Particle-size analysis of Soil, D. 422-63 (Reapproved 1972) Annual Book of ASTM Standards. Part, 1974, 19, 70-80.
16-ISO 17892-4 :2016, Reconnaissance et essais géotechniques - Essais de laboratoire sur les sols — Partie 4: Détermination de la distribution granulométrie des particules, 2016.

17-ISO 10545-4 :2019, Carreaux et dalles céramiques - Partie 4: Détermination de la résistance à la flexion et de la force de rupture, 2019.

18-ISO 10545-3 :2018, Carreaux et dalles céramiques - Partie 3: Détermination de l'absorption d'eau, de la porosité ouverte, de la densité relative apparente et de la masse volumique globale, 2018.

19-J. Goupy, Pratiquer les Plans d'Expériences : Dunod. Paris, 2005, 560.

20-J. Gharsalli, R. Rkik, H. Zouari, F. Turki, M. Chaabane, Composition and Ceramic Properties of Carbonate-Bearing: Illitic Clays from North-Eastern Tunisia,Verres, Céramiques\& Composites, 2011, 1, 4-15.

21-N. El Yakoubi, M. Aberkan, M. Ouadia, Potentialité d'utilisation d'argiles marocaines de Jbel Kharrou dans l'industrie céramique Use potentialities of Moroccan clays from the Jbel Kharrou area in the ceramic industry, Comptes Rendus Geoscience, 2006, 338, 693-702.

22-ISO 13006 :2018, Carreaux et dalles céramiques - Définitions, classification, caractéristiques et marquage, 2018.

23-W. Chih-Huang, L. Deng-Fong, C. Pen-Chi, Utilization of sludge as brick materials, Advances in Environmental Research, 2003, 7, 679-685.

24-M. Sawadogo, L. Zerbo, M. Seynou, B. Sorgho, R. Ouedraogo, Propriétés technologiques de carreaux céramiques à base d'argiles, influence d'un talc naturel, Chemistry \& Chemical Engineering, Biotechnology, Food Industry, 2014, 15, 231-238. 